\title{
Pelatihan Keterampilan Membuat Hiasan Busana (Embroidery) Pada Masyarakat Kelurahan Majener Kabupaten Sorong
}

\author{
Febry Jein Andjar ${ }^{1}$, Retno Dewi Wijiastuti ${ }^{2}$, Addiyat Nova ${ }^{3}$ \\ 1, 2, 3 Fakultas Ekonomi, Universitas Muhammadiyah Sorong, Papua Barat, Indonesia \\ Email: febryojaneth@gmail.com
}

\begin{abstract}
ABSTRAK
Kelurahan Majener yang wilayahnya berada di wilayah Kabupaten Sorong dengan kepadatan penduduk yang sudah lumayan tinggi. Sehingga untuk dapat memenuhi kemandirian perlu diadakan program pelatihan dari pemerintah. Pelatihan tersebut diadakan dengan tujuan untuk meningkatkan taraf kehidupan dengan memanfaatkan peluang usaha yang ada. Kegiatan Pelatihan bertempat di Gedung Serba Guna Kelurahan Majener. Adapun peserta pelatihan terdiri dari ibu-ibu rumah tangga dan anggota PKK (Pemberdayaan dan Kesejahteraan Keluarga) Kelurahan Majener. Total peserta pelatihan yakni 50 orang. Pelatihan dilakukan dengan meyiapkan tempat kerja dan alat, yang dilajutkan dengan membuat desain hiasan busana mulai dari memperkenalkan teknik dan juga bentuk dari ragam hias itu sendiri. Setelah mempraktekkan, peserta kemudian diberi kesempatan untuk mencontohkan setiap tahapan. Antusiasme peserta yang luar biasa dalam pelatihan membuat hiasan busana yang merupakan hal yang baru bagi peserta sehingga seringkali tejadi diskusi disela-sela praktek yang dilakukan, dan pemateri masih terus mendampingi bahkan selalu mengulang rangkaian proses hingga peserta benar-benar mahir dan bisa melakukannya sendiri di rumah. Pelatihan membuat hiasan busana dapat menjadi salah satu alternatif usaha dalam bidang busana, sehingga diharapkan dapat meningkatkan taraf kehidupan khususnya masyarakat Kelurahan Majener.
\end{abstract}

Kata Kunci : Pelatihan, Hiasan Busana, Kelurahan Majener.

\begin{abstract}
Majener Village whose territory is in the Sorong Regency area with a fairly high population density. So that to be able to fulfill independence it is necessary to hold a training program from the government. The training was held with the aim of improving the standard of living by taking advantage of existing business opportunities. The training activities took place at the Multipurpose Building, Majener Village. The training participants consisted of housewives and members of the PKK (Family Empowerment and Welfare) Majener Village. The total number of training participants is 50 people. The training is carried out by preparing workplaces and tools, which is continued by making fashion decoration designs starting from introducing techniques and also the form of the decoration itself. After practicing, participants are then given the opportunity to model each stage. The extraordinary enthusiasm of the participants in the training to make clothing decorations is something new for the participants so that often there are discussions between the practices that are carried out, and the presenters are still accompanying them and even always repeat the series of processes until the participants are truly proficient and can do it themselves at home. Training in making clothing decorations can be an alternative business in the field of clothing, so that it is expected to improve the standard of life, especially the people of Majener Village.
\end{abstract}

Keywords: Training, Clothing Decoration, Majener Village.

\section{PENDAHULUAN}

Era globalisasi memiliki pengaruh yang cukup besar terhadap aspek kehidupan manusia, salah satunya adalah bidang fashion. Kebutuhan akan fashion tidak dapat dipisahkan dari kehidupan manusia sehari-hari (Maryam et al., 2014). Fashion berkaitan erat dengan gaya hidup (life style) seseorang sehingga fashion selalu berkembang sesuai ilmu pengetahuan, teknologi dan seni (Citra Kunia putri dan trisna insan Noor, 2013). Fashion menjadi bagian yang tidak dapat dilepaskan dari penampilan dan gaya keseharian. Benda-benda seperti baju dan aksesoris yang dikenakan 
bukanlah sekadar penutup tubuh dan hiasan, lebih dari itu juga menjadi sebuah alat komunikasi untuk menyampaikan identitas pribadi. Dalam perkembangan selanjutnya fashion tidak hanya menyangkut soal busana dan aksesoris semacam perhiasan seperti kalung dan gelang, akan tetapi benda-benda fungsional lain yang dipadukan dengan unsur-unsur desain yang canggih dan unik menjadi alat yang dapat menunjukkan dan mendongkrak penampilan si pemakai (Hendariningrum \& Susilo, 2008).

Mengingat bahwa dunia pendidikan saat ini berkaitan erat dengan dunia kerja, dimana konsep pendidikan nasional mengacu kepada penyiapan tenaga kerja siap pakai. Tenaga kerja lulusan lembaga pendidikan formal maupun non formal harus siap ditempatkan dalam lapangan pekerjaan yang sesuai dengan bidang atau jenjang pendidikannya. Pendidikan dituntut untuk mampu menyikapi tenaga kerja yang terampil guna memenuhi tuntutan kebutuhan tenaga kerja. Hal tersebut bisa juga tercapai melalui pendidikan non formal. Pendidikan Non Formal adalah pendidikan yang berhadapan langsung dengan masyarakat / peserta didik yang terbatas, baik dari segi ekonomi (kemiskinan), segi pendidikan (putus Sekolah), segi sosial (pengangguran), segi sumber daya manusia (rendahnya keterampilan yang dimiliki) dan lain sebagainya. Salah satu institusi pendidikan dari Pendidikan Non Formal yang memiliki peran penting dalam upayanya memberdayakan masyarakat adalah dengan melalui pendidikan dan pelatihan kerja (Riwayani \& Irmawati, 2017).

Pelatihan merupakan salah satu usaha dalam meningkatkan mutu sumber daya manusia dalam dunia kerja. Pelatihan sering dijadikan sarana guna menambah ilmu, wawasan dan kreatifitas sehingga membuat mereka mandiri dan berani membuka usaha sendiri untuk dapat meningkatan taraf ekonominya (Suryantikasari et al., 2020). Peningkatan ekonomi adalah perubahan yang lebih baik dari yang sebelumnya, dalam upaya pemenuhan kebutuhan ekonomi keseharian dalam keluarga. Hubungan keluarga dari aspek ekonomi merupakan masalah yang paling pokok dalam rumah tangga karena dalam keluarga yang menjadi pendorong sejahteranya rumah tangga adalah dibidang ekonomi. Fungsi ekonomi memegang peranan penting dalam sebuah keluarga karena merupakan faktor mendasar untuk menunjang kebutuhan fisik keluarga. Salah satu aktivitas yang dapat meningkatkan taraf ekonomi yaitu dengan membuat kerajinan menghias busana. Menghias busana adalah memperindah segala sesuatu yang dipakai oleh manusia baik untuk dirinya sendiri maupun untuk keperluan rumah tangga (Siswoyo, 2016). Menghias busana dapat dilakukan dengan berbagai teknik (Asmaningrum et al., 2013), salah satunya adalah teknik sulaman. Sulaman 
adalah hiasan yang dibuat di atas kain atau bahan-bahan lain dengan jarum jahit dan benang. Selain benang, hiasan untuk sulaman dapat menggunakan bahan-bahan seperti potongan logam, mutiara, manik-manik, bulu burung, dan payet. Penerapan hiasan pada busana dalam bentuk sulaman menjadi daya tarik tersendiri bagi konsumen. Sulaman dapat menjadi salah satu alternatif usaha dalam bidang busana (Maryam et al., 2014). Hiasan busana menjadi faktor utama dalam menentukan nilai jual, kualitas serta nilai estetika dari suatu busana. Selain itu, hiasan merupakan hal yang terpenting khususnya dalam bidang busana (Hati, 2009).

Oleh karena itu, Standar kompetensi membuat hiasan pada busana merupakan salah satu kompetensi yang termasuk pada program produktif yang tujuannya yaitu untuk meningkatkan kreatifitas dan dapat menciptakan motif-motif baru, menciptakan model busana yang unik dan bisa menjadi suatu hobi yang dapat kita kembangkan. Namun pelatihan membuat hiasan pada busana membutuhkan sumber daya manusia yang mempunyai skill agar lebih cepat mencapai tujuan penciptaan hiasan tersebut (Nuraiyah \& Setiawati, n.d.).

Pelatihan dilaksanakan di Kelurahan Majener karena tingkat pendapatan masyarakatnya yang masih rendah, sehingga diharapkan dengan diadakan pelatihan tersebut masyarakat khususnya ibu-ibu bisa membuka peluang usaha guna meningkatkan taraf kehidupannya.

\section{METODE PENELITIAN}

\section{Tempat, dan Peserta}

Kegiatan pelatihan dilaksanakan di Kelurahan Majener, bertempat di Gedung Serbaguna Kelurahan Majener. Adapun peserta pelatihan terdiri dari ibu-ibu rumah tangga dan anggota PKK Kelurahan Majener. Total peserta pelatihan yakni 50 orang.

\section{Bahan dan Alat Pelatihan}

Adapun bahan dan alat yang digunakan dalam pelatihan ini yaitu :

\section{Alat}

Alat-alat yang digunakan yaitu jarum tangan dengan berbagai ukuran, jarum pentul, gunting besar/gunting kecil, tudung jari, pendedel, rader arbon jahit dan ram atau pembidangan.

\section{Bahan}

Bahan utama yaitu kain yang akan dihias dan bahan penunjang merupakan bahan yang digunakan untuk membuat hiasan itu sendiri seperti aneka jenis benang, aneka jenis pita, aneka jenis tali, manik, payet, batu-batuan dan lain-lain. 


\section{Tahapan Pelatihan}

Tahap-tahap yang harus dilakukan yaitu menyiapkan tempat kerja dan alat, membuat desain hiasan busana, memindahkan desain pada busana, membuat hiasan pada busana, mengemas busana yang sudah dihias, dan menyimpannya.

\section{HASIL DAN PEMBAHASAN}

Sebelum kita membuat hiasan atau melakukan pekerjaan menghias baik itu menghias lenan rumah tangga ataupun menghias busana terlebih dahulu perlu disiapkan tempat kerja, alat serta bahan yang dibutuhkan untuk menghias Agar pekerjaan dapat berjalan efektif dan efisien maka tempat atau ruang kerja hendaklah ditata sebaik mungkin dan semua alat dan bahan yang di butuhkan untuk menghias ditata sesuai dengan kegunaannya.

\section{Membuat Desain Hiasan Busana}

Menghias dalam Bahasa Inggris berasal dari kata "to decorate” yang berarti menghias atau memperindah. Dalam busana menghias berarti memperindah segala sesuatu yang dipakai oleh manusia baik untuk dirinya sendiri maupun keperluan rumah tangga. Benda yang dipakai untuk diri sendiri antara lain blus, rok, celana, tas, topi dan lain-lain, sedangkan untuk keperluan rumah tangga diantaranya yaitu taplak meja, bed cover, bantal kursi, gorden, dan lain-lain.

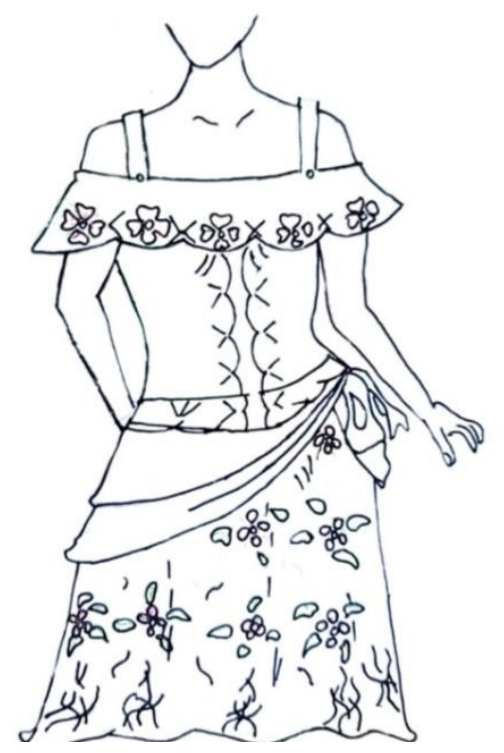

Gambar 1. Desain Busana Untuk Wanita

Ditinjau dari tekniknya, menghias kain dibedakan atas 2 macam yaitu menghias permukaan bahan yang sudah ada dengan bermacam-macam tusuk hias baik yang menggunakan tangan maupun 
menggunakan mesin dan dengan cara membuat bahan baru yang berfungsi untuk menghias benda. Menghias permukaan kain atau bahan yaitu berupa aneka teknik hias seperti sulaman, lekapan, mengubah corak, smock, kruisteek, terawang, dan metelase.

Desain hiasan merupakan desain yang dibuat untuk meningkatkan untuk meningkatkan mutu dari desain struktur suatu benda. Desain hiasan ini terbentuk dari berbagai susunan seperti garis, arah, bentuk, ukuran, tekstur, value, dan warna. Bentuk dan warna merupakan unsur yang sangat mempengaruhi tampilan sebuah desain hiasan. Desain hiasan dapat dibuat dari berbagai bentuk ragam hias. Adapun jenis-jenis ragam hias yang dapat digunakan untuk menghias bidang atau benda yaitu :

1. Bentuk naturalis, yaitu bentuk yang dibuat berdasarkan bentuk-bentuk yang ada dialam sekitar seperti, bentuk tumbuh-tumbuhan, hewan, batu-batuan, dan lain-lain.

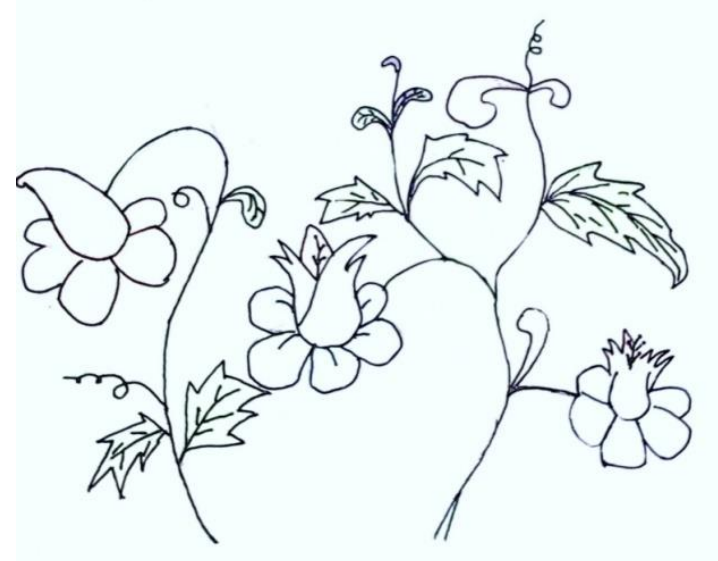

\section{Gambar 2. Bentuk Naturalis}

2. Bentuk geometris, yaitu bentuk-bentuk yang mempunyai bentuk teratur dan dapat diukur menggunakan alat ukur seperti, segi empat, segi tiga, lingkaran, dan lain-lain.



Gambar 3. Bentuk Geometris 
3. Bentuk dekoratif, yaitu bentuk yang berasal dari bentuk naturalis dan bentuk geometris yang sudah distilasi atau direngga sehingga muncul bentuk baru tetapi ciri khas bentuk tersebut masih terlihat.

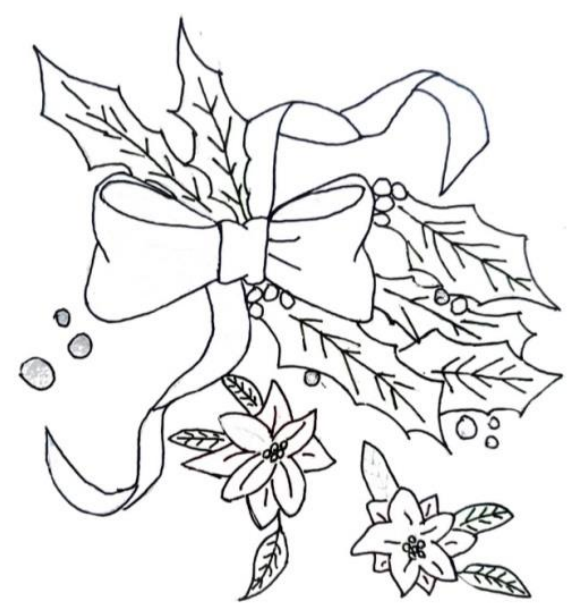

Gambar 4. Bentuk Dekoratif

\section{Desain Hiasan Dibuat Sesuai Rencana}

Membut motif adalah merupakan seni menghias yaitu suatu rasa perasaan seni yang diwujudkan dalam berbagai bentuk. Jadi pengertian secara keseluruhan adalah seni memindahkan atau seni menghias pada busana dan kebutuhan rumah tangga lain nya agar kelihatan menarik. Tujuan untuk membuat hiasan/motif hias adalah mempertinggi nilai benda, menambah keindahan benda, dan menarik perhatian.

Motif dasar merupakan dasar pembuatan motif hias berupa garis lurus, garis zigzag, dan garis lengkung. Bentuk garis lurus sebagai pemula menyulam adalah membuat garis-garis lurus untuk jahitan tangan supaya dapat menggunakan pemindangan dengan benar. Bentuk garis zigzag nerupakan lanjutan dari bentuk garis lurus, garis motif dasar bentuk zigzag. Bentuk garis lengkung adalah motif dasar dari pengulangan bentuk zigzag

\section{Memindahkan Desain Pada Busana.}

Pola hias yang sudah dirancang untuk busana atau untuk keperluan lenan rumah tangga dipindahkan terlebih dahulu pada bahan yang akan dihias. Cara memindahkan desain hiasan ini tergantung pada kain yang digunakan. Untuk kain yang tebal atau tidak transparan dapat menggunakan karbon jahit. Karbon jahit diletakkan diatas kain atau antara bagian baik kain dengan dengan kertas desain motif, kemudian motif ditekan menggunakan pensil sehingga motif pindah 
ke atas kain. Sedangkan untuk kain yang tipis atau transparan dapat langsung dijiplak menggunakan pensil, yang mana kertas motif diletakkan di bawah bahan.

\section{Menyimpan Kain/Busana Yang Telah Dihias}

Busana atau kain yang telah dihias hendaklah sudah bersih atau sudah dicuci ketika akan disimpan. Cara penyimpanannya dapat dilakukan dengan cara digantung pada Hanger dan ditutup dengan plastik sehingga terhindar dari debu. Jika penyimpanan dilakukan dalam lemari maka aturlah posisinya agar tidak terlalu berdempet sehingga ragam hias pada busana tidak rusak.

Jika bahan yang dihias masih berupa lembaran kain yang akan dibuat menjadi busana atau yang dibuat dengan tujuan untuk dijual, maka lipatlah bahan dengan posisi lipatan kain tidak mengganggu hiasan yang ada, kemudian di gantung menggunakan hanger.

\section{SIMPULAN}

Pelatihan membuat hiasan busana mendapat respon yang sangat luar biasa dari peserta pelatihan dalam hal ini Kelurahan Majener, terbukti kehadiran warga yakni 50 orang, bahkan mereka meminta pemateri bisa melakukan pelatihannya secara berkesinambungan di Kelurahan Majener di masing-masing RT yang ada dalam lingkup Kelurahan Majener. Pelatihan pembuatan hiasan busana yang diberikan kepada warga dari segi biaya dan input atau alat yang digunakan sangat terjangkau dan mudah di cari.

Selain itu pelatihan membuat hiasan busana bisa meningkatkan kreatifitas mereka dan menciptakan hiasan sesuka hati dan tidak memerlukan tenaga yang berlebih atau waktu yang terbatas agar warga tetap bisa melakukan aktivitas menghias busana atau lenan mereka dan proses pembuatan yang lumayan sulit di karenakan menggunakan ketekunan dan ketelitian, maka dari itu dengan adanya pelatihan pembuatan hiasan akan sangat membantu warga untuk menciptakan atau mengekspresikan kreatifitas mereka.

\section{DAFTAR PUSTAKA}

Asmaningrum, R., Teknik, F., Surabaya, U. N., Sulandjari, S., Teknik, F., \& Surabaya, U. N. (2013). Peran Tutor Sebaya Dalam Pelatihan Lekapan Kain Pada Busana. 02.

Citra Kunia putri dan trisna insan Noor, 2011. (2013). Analisis Pendapatan Dan Tingkat Kesejahteraan Rumah Tangga Petani, 53(9), 1689-1699.

Hati, I. P. (2019). (2009). Bab I Pendahuluan . Journal Information, 10(2008), 1-16. 
Hendariningrum, R., \& Susilo, E. M. (2008). Fashion dan Gaya Hidup: Identitas dan Komunikasi. Ilmu Komunikasi, 6(2), 25-32. http://jurnal.upnyk.ac.id/index.php/komunikasi/article/viewFile/38/42

Maryam, N. R., Hasil, K., Membuat, B., Pada, H., Terhadap, B., \& Membuka, K. (2014). Norma Rahmi Maryam, 2014 Kontribusi Hasil Belajar Membuat Hiasan Pada Busana Terhadap Kesiapan Membuka Usaha Sulaman Universitas Pendidikan Indonesia | repository.upi.edu | perpustakaan.upi.edu. 1-5.

Nuraiyah, D., \& Setiawati, A. (n.d.). PENERAPAN HASIL BELAJAR “ MEMBUAT HIASAN BUSANA " PADA PEMBUATAN BUSANA PESTA ANAK salah satunya yaitu Program Keahlian Busana Butik . Program Keahlian Busana keterampilan yang dapat dipilih oleh yang dikembangkan di SMK NEGRI 6 NEGRI 6 Garut Program Keah.

Riwayani, R., \& Irmawati, I. (2017). Efektivitas Pendidikan dan Pelatihan Membordir di BLKI Makassar. Seminar Nasional Lembaga Penelitian UNM, 179-184. http://ojs.unm.ac.id/semnaslemlit/article/view/4004

Siswoyo, N. A. (2016). Peningkatan Ekonomi Keluarga Melalui Aktivitas Komunitas Sulam Pita di Kampung 1001 Malam Surabaya. E-Journal, 05(01).

Suryantikasari, F., Teknik, F., Surabaya, U. N., Kharnolis, M., Teknik, F., \& Surabaya, U. N. (2020). MENGHIAS HIJAB SYAR ' I DENGAN SULAM PITA EROPA MENGGUNAKAN HANDOUT PADA IBU PKK DI DESA BANJAREJO KECAMATAN NGADILUWIH. 09. 